\title{
Violence, peace and peace research ${ }^{1}$
}

\author{
Violência, paz e pesquisa para a paz
}

\author{
Violencia, paz e investigación para la paz
}

\section{Johan Galtung}

- Founder of International Peace Research Institute, Oslo

- $\quad$ Principal founder of Peace and Conflict Studies

- $\quad$ Founder of Transcend University Press

- $\quad$ Author of "A structural theory of Imperialism", Journal of Peace Research, v. 8, n. 2, p. 81, 1971; Peace by peaceful means: peace and conflict, development and civilization, Oslo: International Peace Research Institute, 1996; Violencia cultural, Gernika-Lumo: Gernika Gogoratuz Centro de Investigación por la Paz, 2003, n. 14 (Spanish edition); 50 Years - 100 peace \& conflict perspectives, Grenzach-Whylen: Transcend University Press, 2008; Theory of conflict-Overcoming direct violence, Grenzach-Whylen: Transcend University Press, 2010; and other publications.

- E-mail: tup@transcend.org

1 First published in Jounal of Peace Research, v. 6, n. 3, p. 167-191, 1969, by Sage Publications Ltd. The present article (PRIO-publication No.23-9) is a revised version of talks originally presented by the author at the Oslo Conference on the plan for a peacemaker's academy, organized jointly by the Peacemakers' Academy Committee, Vermont and the International Peace Research Institute, Oslo, 14-17 November 1968; at the peace research seminar organized by the Gandhian Institute of Studies, Varanasi, 8-9 March 1969; at the meeting of the Japan Peace Research Group Tokyo, 27 March 1969; at a seminar organized by the Seminar for Peace and Conflict Research, Lund, 26 April 1969, and at the international seminar organized by the Centro Studi e Iniziative, Partinico, 3-4 May 1969. I am indebted to the organizers of these meetings, Randolph Major, Sugata Dasgupta, Hisako Ukita, Hakan Wiberg and Danilo Dolci and to many participants for highly stimulating comments and criticism. But special gratitude should be expressed to Herman Schmid, Lund University, Sweden, for his lucid and important criticism of some concepts of peace research (1968). Although I agree neither with his critique nor with his proposals, and feel that his way of presenting my own views is misleading, there are certainly few persons who have stimulated discussion and rethinking in this fundamental field so much. However, the present article is not a systematic answer to his arguments, but rather an effort, partly stimulated by him, to indicate what to the present author seems to be a fruitful way of thinking about violence, peace and peace research. 


\section{Abstract}

In its trajectory as a scientific field, the peace research recognizes that defining "peace" is, in fact, an important part of the scientific strategy. Thus, the field has been dedicated to conceptualizing peace in a broad, dialogic, and complex manner, as complex and diverse as the world is. Likewise, conceptualizing violence is an intricate task since, more important than reaching a definition or typologies - as there is, obviously, many types of violence -, indicating theoretically significant dimensions of violence is essential, as it leads us to thinking, researching, and potentially acting on the most serious problems of Mankind. If the peace action must be considered because it is an action against violence, then the concept of violence must be broad enough to cover the most significant varieties and, in addition, must be specific enough to serve as a basis for concrete action. Given this perspective, this articles aims at presenting a theoretical-conceptual reflection about peace and violence in the context of the critical perspective of peace studies.

KEYWORDS: PEACE RESEARCH • PEACE • VIOLENCE • PEACE STUDIES,

\section{Resumo}

Em sua trajetória como campo científico, a peace research ou "pesquisa para a paz" reconhece que definir "paz" é, de fato, uma parte importante de uma estratégia científica. Dessa forma, tem se dedicado a conceituar paz de forma ampla, dialógica e complexa, tal como diverso e complexo é o mundo. Do mesmo modo, conceituar a violência se torna tarefa igualmente complexa, uma vez que, mais importante do que chegar a uma definição ou a tipologias - pois há, obviamente, muitos tipos de violência -, indicar dimensões teoricamente significativas de violência é, efetivamente, fundamental, posto que pode nos levar a pensar, pesquisar e, potencialmente, agir diante dos problemas mais graves da humanidade. Se a peace action deve ser considerada porque é uma ação contra a violência, então o conceito de violência deve ser amplo o suficiente para incluir as variedades mais significativas e, além disso, deve ser específico o bastante para servir de base para uma ação concreta. Nessa perspectiva, este artigo pretende apresentar uma reflexão teórico-conceitual sobre paz e violência no contexto da perspectiva crítica dos estudos para a paz (peace studies).

PALAVRAS-CHAVE: PESQUISA PARA A PAZ •PAZ •VIOLÊNCIA • ESTUDOS PARA A PAZ.

\section{Resumen}

En su trayectoria como campo científico, la Peace Research o Investigación para la Paz reconoce que definir "paz" es, de hecho, una parte fundamental de una estrategia científica. En ese contexto, se ha dedicado a conceptualizar paz de forma amplia, dialógica y compleja, tal como diverso y complejo es el mundo. Del mismo modo, definir violencia se convierte en una labor igualmente compleja, una vez que más importante que llegar a una definición o a tipologías, -pues hay, evidentemente, muchos tipos de violencia- indicar dimensiones teóricamente significativas de violencia es efectivamente lo fundamental, una vez que nos puede llevar a pensar, investigar y, potencialmente, actuar ante los problemas más graves de la humanidad. Si la peace action debe ser considerada porque es una acción contra la violencia, el mismo concepto de violencia debe ser lo suficientemente amplio para incluir las variedades más significativas y, además, también debe ser lo suficientemente específico para servir de base para una acción concreta. En esa perspectiva, este artículo pretende presentar una reflexión teórico conceptual sobre paz y violencia en el contexto de la perspectiva crítica de los Estudios para la Paz (Peace Studies). 


\section{INTRODUCTION}

$\mathrm{n}$ the present paper we shall be using the word 'peace' very many times. Few words are so often used and abused perhaps, it seems, because 'peace' serves as a means of obtaining verbal consensus - it is hard to be all-out against peace. ${ }^{2}$ Thus, when efforts are made to plead almost any kind of policy - say technical assistance, increased trade, tourism, new forms of education, irrigation, industrialization, etc. - then it is often asserted that that policy, in addition to other merits, will also serve the cause of peace. This is done regardless of how tenuous the relation has been in the past or how dubious the theory justifying this as a reasonable expectation for the future. Such difficulties are avoided by excluding any reference to data from the past or to theories about the future.

This practice is not necessarily harmful. The use of the term 'peace' may in itself be peace-productive, producing a common basis, a feeling of communality in purpose that may pave the ground for deeper ties later on. The use of more precise terms drawn from the vocabulary of one conflict group, and excluded from the vocabulary of the opponent group, may in itself cause dissent and lead to manifest conflict precisely because the term is so clearly understood. By projecting an image of harmony of interests the term 'peace' may also help bring about such a harmony. It provides opponents with a one-word language in which to express values of concern and togetherness because peace is on anybody's agenda. ${ }^{3}$

One may object that frequent use of the word 'peace' gives an unrealistic image of the world. Expressions like 'violence', 'strife', 'exploitation' or at least 'conflict', 'revolution' and war should gain much higher frequency to mirror semantically a basically non-harmonious world. But leaving this major argument aside for the moment, it is obvious that some level of precision is necessary for the term to serve as a cognitive tool. At this point, of course, nobody has any monopoly on defining 'peace'. But those who use the term frequently in a research context, as peace researchers (will do) do, will at least have gained some experience when it comes to definitions that should be avoided for one reason or another.

To discuss the idea of peace we shall start from three simple principles:

1. The term 'peace' shall be used for social goals at least verbally agreed to by many, if not necessarily by most.

2. These social goals may be complex and difficult, but not impossible, to attain.

3. The statement peace is absence of violence shall be retained as valid.

The third principle is not a definition, since it is a clear case of obscurum per obscurius. What we intend is only that the terms 'peace' and 'violence' be linked to each other such that 'peace' can be regarded as 'absence of violence'. The reasons at this early point in our semantical excursion, are twofold: the statement is simple and in agreement with common usage, and defines a peaceful social order not as a point but as region - as the vast region of social orders from which violence is absent. Within this region a tremendous amount of variation is still possible, making an orientation in favor of peace compatible with a number of ideologies outlining other aspects of social orders.

2 This point is elaborated further in Theories of Peace (forthcoming), Chapter 1.1.

3 This, of course, is not strictly true. It was not on Fascist or nazi agendas, nor is it on the agenda of contemporary revolutionary thinking. However, even for these cases violence is not an end, but rather a means to overcome obstacles impeding the realization of a future order, the millennium, the communist society, etc.; these future orders do not seem to contain violence. But this is hardly a universal human invariant. The Viking paradise looks violent, and warlike tribes/societies like the Pathans would probably put complete absence of violence last on the agenda, if at all. 
Everything now hinges on making a definition of 'violence'. This is a highly unenviable task, and the suggestions will hardly be satisfactory to many readers. However, it is not so important to arrive at anything like the definition, or the typology - for there are obviously many types of violence. More important is to indicate theoretically significant dimensions of violence that can lead thinking, research and, potentially, action, towards the most important problems. If peace action is to be regarded highly because it is action against violence, then the concept of violence must be broad enough to include the most significant varieties, yet specific enough to serve as a basis for concrete action.

Thus, the definition of 'peace' becomes a major part of a scientific strategy. It may depart from common usage by not being agreed to 'by most' (consensus not required), yet should not be entirely subjectivistic ('agreed to by many'). It should depict a state of affairs the realization of which is not utopian ('not impossible to obtain'), yet not on the immediate political agenda ('complex and difficult'). And it should immediately steer one's attention towards problems that are on the political, intellectual, and scientific agenda of today, and tomorrow. ${ }^{2}$

\section{ON THE DEFINITION AND DIMENSIONS OF 'VIOLENCE'}

As a point of departure, let us say that violence is present when human beings are being influenced so that their actual somatic and mental realizations are below their potential realizations. This statement may lead to more problems than it solves. However, it will soon be clear why we are rejecting the narrow concept of violence - according to which violence is somatic incapacitation, or deprivation of health, alone (with killing as the extreme form), at the hands of an actorwho intends this to be the consequence. If this were all violence is about, and peace is seen as its negation, then too little is rejected when peace is held up as an ideal. Highly unacceptable social orders would still be compatible with peace. Hence, an extended concept of violence is indispensable but that concept should be a logical extension, not merely a list of undesirables.

The definition points to at least six important dimensions of violence. But first some remarks about the use of the key words above, 'actual' and 'potential'. Violence is here defined as the cause of the difference between the potential and the actual, between what could have been and what is. Violence is that which increases the distance between the potential and the actual, and that which impedes the decrease of this distance. Thus, if a person died from tuberculosis in the eighteenth century it would be hard to conceive of this as violence since it might have been quite unavoidable, but if he dies from it today, despite all the medical resources in the world, then violence is present according to our definition. Correspondingly, the case of people dying from earthquakes today would not warrant an analysis in terms of violence, ${ }^{4}$ but the day after tomorrow, when earthquakes may become avoidable, such deaths may be seen as the result of violence. In other words, when the potential is higher than the actual is by definition avoidable and when it is avoidable, then violence is present.

When the actual is unavoidable, then violence is not present even if the actual is at a very low level. A life expectancy of thirty years only, during the Neolithic period, was not an expression of violence, but the same life-expectancy today (whether due to wars, or social injustice, or both) would be seen as violence according to our definition.

Thus, the potential level of realization is that which is possible with a given level of insight and resources. If insight and/or resources are monopolized by a group or class or are used for other purposes, then the actual level falls below the potential

4 But what if a social order is such that some people live well in solid, concrete houses and others in shacks that crumble under the first quake, killing the inhabitants? In other words, even if the natural disaster is unavoidable, differential social impact may have been avoidable. This may certainly justify the use of the term 'structural violence' for such differential housing standards, not only because of differential exposure to earthquakes (as in the earthquake zone in Western Sicily), but because of implications for differential health standards in general, educational possibilities, and so on and so forth. Whether it justifies the use of such epithets as 'violent' or 'assassin' to the people sustaining such social structures, or (which is not quite the same) to the people on top of such social structures, is another matter. 
level, and violence is present in the system. In addition to these types of indirect violence there is also the direct violence where means of realization are not withheld, but directly destroyed. Thus, when a war is fought there is direct violence since killing or hurting a person certainly puts his 'actual somatic realization' below his 'potential somatic realization \But there is also indirect violence insofar as insight and resources are channeled away from constructive efforts to bring the actual closer to the potential. ${ }^{5}$

The meaning of 'potential realizations' is highly problematic, especially when we move from somatic aspects of human life, where consensus is more readily obtained ${ }^{6}$, to mental aspects. Our guide here would probably often have to be whether the value to be realized is fairly consensual or not, although this is by no means satisfactory. For example, literacy is held in high regard almost everywhere, whereas the value of being Christian is highly controversial. Hence, we would talk about violence if the level of literacy is lower than what it could have been, not if the level of Christianity is lower than what it could have been. We shall not try to explore this difficult point further in this context, but turn to the dimensions of violence.

To discuss them, it is useful to conceive of violence in terms of influence, as indicated in the statement we used as a point of departure above. A complete influence relation presupposes an influencer, an influence, and a mode of influencing. ${ }^{7}$ In the case of persons, we can put it very simply: a subject, an object, and an action. But this conception of violence in terms of a complete interpersonal influence relation will lead us astray by focusing on a very special type of violence only; also truncated versions where either subject or object or both are absent are highly significant. To approach this we shall start with two dimensions characterizing the violent action itself, or the mode of influence.

The first distinction to be made is between physical and psychological violence. The distinction is trite but important mainly because the narrow concept of violence mentioned above concentrates on physical violence only. Under physical violence human beings are hurt somatically, to the point of killing. It is useful to distinguish further between 'biological violence', which reduces somatic capability (below what is potentially possible), and 'physical violence as such', which increases the constraint on human movements (Galtung, 1965, p.230-234) - as when a person is imprisoned or put in chains, but also when access to transportation is very unevenly distributed, keeping large segments of a population at the same place with mobility a monopoly of the selected few. But that distinction is less important than the basic distinction between violence that works on the body, and violence that works on the soul; where the latter would include lies, brainwashing, indoctrination of various kinds, threats, etc. that serve to decrease mental potentialities. (Incidentally, it is interesting that such English words as 'hurt' and 'hit' can be used to express psychological as well as physical violence: this doubleness is already built into the language.)

5 Since the potential level depends not only on the use and distribution of available resources, but also on insight, a crucial person in this picture is the scientist or anyone who opens for new insights into how old, or new, resources may be utilized. In other words, anyone who makes possible what was formerly not feasible raises the level of potentiality. But the level may also be lowered, perhaps not so often because insight is forgotten (although history is full of such cases too) as because resources become more scarce - for instance due to pollution, hoarding, overutilization, etc. In short, we make no assumption about the shape of the potential realization curve through time, nor do we make any assumption about the corresponding curve for actual realization. In particular we reject the optimistic assumption according to which both curves are monotonously increasing and with a decreasing gap so that there is asymptotic convergence of the actual to the potential, 'until the potentialities of man are fully realized'. This is an ideology, usually in the form of an underlying assumption, not a description or reality. As Bertrand Russell writes (1967, p.221): 'When I was young, Victorian optimism was taken for granted. It was thought that freedom and prosperity would spread gradually throughout the world by an orderly process, and it was hoped that cruelty, tyranny and injustice would continually diminish. Hardly anyone was haunted by the fear of great wars. Hardly anyone thought of the nineteenth century as a brief interlude between past and future barbarism -.' In short, let us make no assumptions, but focus on the causes for a discrepancy between the curves, admitting for a lag in the application and distribution of new insights; whether they are called technological or social.

6 However, it is by no means obvious how potential life-span should be defined. One cannot use the age at death of the oldest person dying today or this year; this may be too low because he does not benefit from possible advances in hygiene etc. made too late to have an impact on him, or not yet made, and it may be too high because he is specially advantaged genetically. But the average of the $\mathrm{p} \%$ of the social order benefiting fully from insight and resources already available should at least yield a basis for an estimate of what is possible today.

7 In an article 'On the Meaning of Nonviolence' (Galtung, 1965), the concept of influence is basic in an effort to analyze the difference between violence and nonviolence, and positive and negative versions of the latter. In the present article the focus is on a typology of violence, not on a typology of non-violence. 
The second distinction is between the negativeand positive approach to influence. (Galtung, 1965, p.230-234) Thus, a person can be influenced not only by punishing him when he does what the influencer considers wrong, but also by rewarding him when he does what the influencer considers right. Instead of increasing the constraints on his movements the constraints may be decreased instead of increased, and somatic capabilities extended instead of reduced. This may be readily agreed to, but does it have anything to do with violence? Yes, because the net result may still be that human beings are effectively prevented from realizing their potentialities. Thus, many contemporary thinkers ${ }^{8}$ emphasize that the consumer's society rewards amply he who goes in for consumption, while not positively punishing him who does not. The system is reward-oriented, based on promises of euphoria, but in so being also narrows down the ranges of action. It may be disputed whether this is better or worse than a system that limits the range of action because of the dysphoric consequences of staying outside the permitted range. It is perhaps better in terms of giving pleasure rather than pain, worse in terms of being more manipulatory, less overt. But the important point is, the awareness of the concept of violence can be extended in this direction, since it yields a much richer basis for discussion.

The third distinction to be made is on the object side: whether or not there is an object that is hurt. Can we talk about violence when no physical or biological object is hurt? This would be a case of what is referred to above as truncated violence, but nevertheless highly meaningful. When a person, a group, a nation is displaying the means of physical violence, whether throwing stones around or testing nuclear arms, there may not be violence in the sense that anyone is hit or hurt, but there is nevertheless the threat of physical violence and indirect threat of mental violence that may even be characterized as some type of psychological violence since it constrains human action. Indeed, this is also the intention: the famous balance of power doctrine is based on efforts to obtain precisely this effect. And correspondingly with psychological violence that does not reach any object: a lie does not become more of a truth because nobody believes in the lie. Untruthfulness is violence according to this kind of thinking under any condition, which does not mean that it cannot be the least evil under some widely discussed circumstances.

Is destruction of things violence? Again, it would not be violence according to the complete definition above, but possibly some 'degenerate' form. But in at least two senses it can be seen as psychological violence: the destruction of things as a foreboding or threat of possible destruction of persons, ${ }^{9}$ and the destruction of things as destruction of something very dear to persons referred to as consumers or owners. ${ }^{10}$

The fourth distinction to be made and the most important one is on the subject side: whether or not there is a subject (person) who acts. Again it may be asked: can we talk about violence when nobody is committing direct violence, is acting? This would also be a case of what is referred to above as truncated violence, but again highly meaningful. We shall refer to the type of violence where there is an actor that commits the violence as personal or direct, and to violence where there is no such actor as structural or indirect. ${ }^{11}$ In both cases individuals may be killed or mutilated, hit or hurt in both senses of these words, and manipulated by means of stick or carrot strategies. But whereas in the first case these consequences can be traced back to concrete persons as actors, in the second case this is no longer meaningful. There may not be any person

8 This is a recurrent theme in Herbert Marcuse, One-dimensional Man (1968), especially Part I, 'One-dimensional Society'.

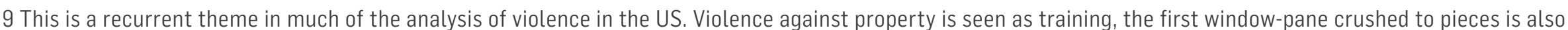

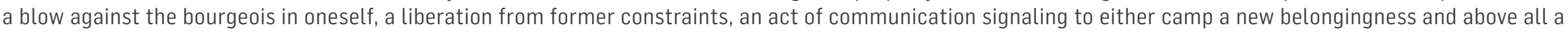
rejection of tacit rules of the game. 'If they can do that to property, what can they do to persons -.

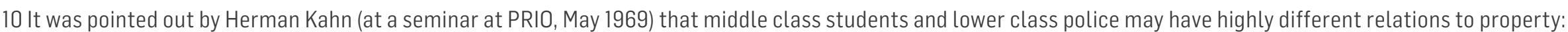

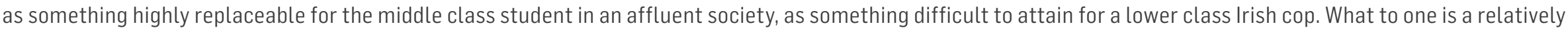

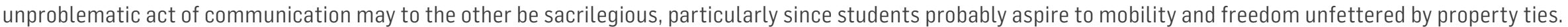


who directly harms another person in the structure. The violence is built into the structure and shows up as unequal power and consequently as unequal life chances. ${ }^{12}$

Resourcesare unevenly distributed, as when income distributions are heavily skewed, literacy/education unevenly distributed, medical services existent in some districts and for some groups only, and so on. ${ }^{13}$ Above all the power to decide over the distribution of resources is unevenly distributed. ${ }^{14}$ The situation is aggravated further if the persons low on income are also low in education, low on health, and low on power - as is frequently the case because these rank dimensions tend to be heavily correlated due to the way they are tied together in the social structure. ${ }^{15}$ Marxist criticism of capitalist society emphasizes how the power to decide over the surplus from the production process is reserved for the owners of the means of production, who then can buy themselves into top positions on all other rank dimensions because money is highly convertible in a capitalist society - if you have money to convert, that is. Liberal criticism of socialist society similarly emphasizes how power to decide is monopolized by a small group who convert power in one field into power in another field simply because the opposition cannot reach the stage of effective articulation.

The important point here is that if people are starving when this is objectively avoidable, then violence is committed, regardless of whether there is a clear subject-action-object relation, as during a siege yesterday or no such clear relation, as in the way world economic relations are organized today. ${ }^{16}$ We have baptized the distinction in two different ways, using the word-pairs personal-structural and direct-indirect respectively.

Violence with a clear subject-object relation is manifest because it is visible as action. It corresponds to our ideas of what drama is, and it is personal because there are persons committing the violence. It is easily captured and expressed verbally since it has the same structure as elementary sentences in (at least Indo-European) languages: subject-verb-object, with both subject and object being persons. Violence without this relation is structural, built into structure. Thus, when one husband beats his wife there is a clear case of personal violence, but when one million husbands keep one million wives in ignorance there is structural violence. Correspondingly, in a society where life expectancy is twice as high in the upper as in the lower classes, violence is exercised even if there are no concrete actors one can point to directly attacking others, as when one person kills another.

12 This is clearly expressed by Stokeley Carmichael in 'Black Power' (1968, p.151):

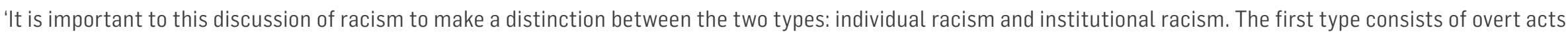

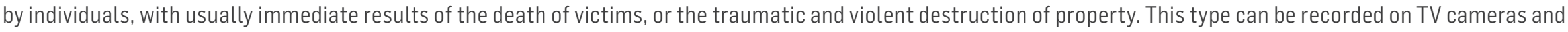
can frequently be observed in the process of commission.

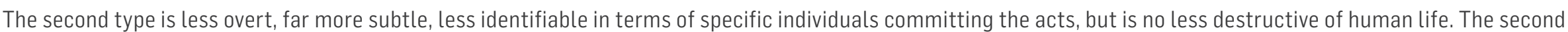

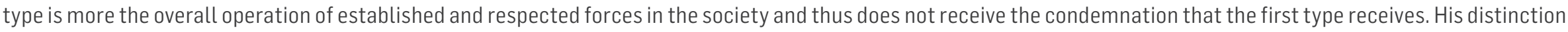

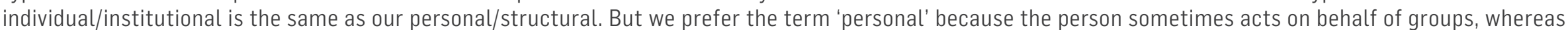

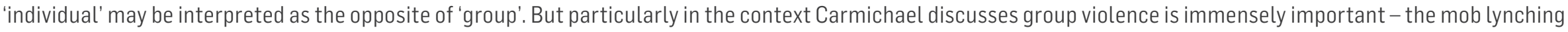

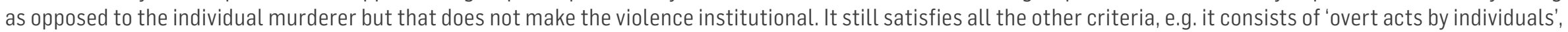
'can be recorded on TV-cameras' (as in a war), etc.'

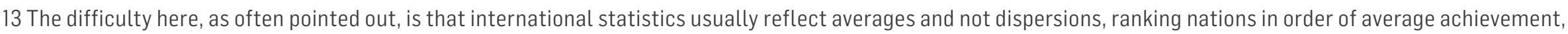

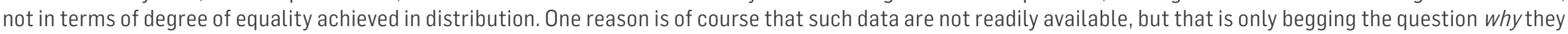

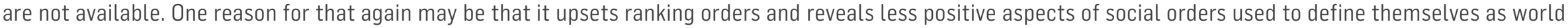

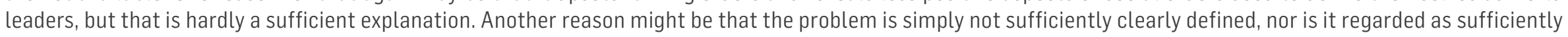
feasible or indeed desirable to decrease dispersions. When this becomes sufficiently crystallized it will also find expressions in international statistics.

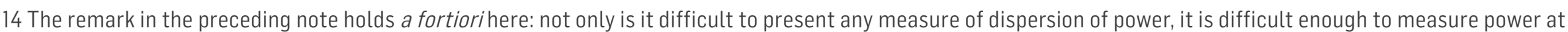

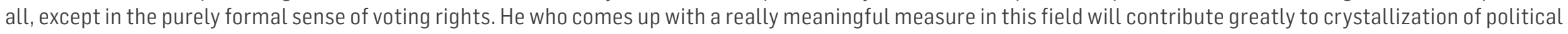
fighting as well as administrative endeavors.

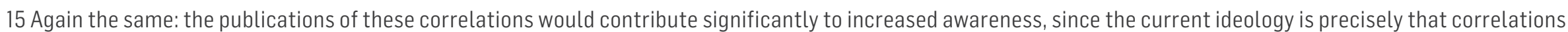
between achieved and ascribed ranks should be as low as possible, preferably zero.

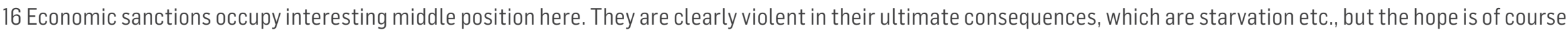

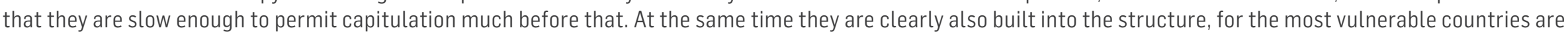

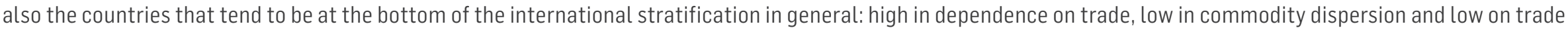
partner dispersion. See Johan Galtung, 'On the Effects of International Economic Sanctions, With Examples from the Case of Rhodesia' (1967a). 
In order not to overwork the word violence we shall sometimes refer to the condition of structural violence as social injustice, ${ }^{17}$ The term 'exploitation' will not be used, for several reasons. First, it belongs to a political vocabulary, and has so many political and emotional overtones that the use of this term will hardly facilitate communication. Second, the term lends itself too easily to expressions involving the verb exploit, which in turn may lead attention away from the structural as opposed to the personal nature of this phenomenon - and even lead to often unfounded accusations about intended structural violence. ${ }^{18}$

The fifth distinction to be made is between violence that is intended or unintended. This distinction is important when guilt is to be decided, since the concept of guilt has been tied more to intention, both in Judaeo-Christian ethics and in Roman jurisprudence, than to consequence (whereas the present definition of violence is entirely located on the consequence side). This connection is important because it brings into focus a bias present in so much thinking about violence, peace, and related concepts: ethical systems directed against intended violence will easily fail to capture structural violence in their nets - and may hence be catching the small fry and letting the big fish loose. From this fallacy it does not follow, in our mind, that the opposite fallacy of directing all attention against structural violence is elevated into wisdom. If the concern is with peace, and peace is absence of violence, then action should be directed against personal as well as structural violence; a point to be developed below.

Sixth, there is the traditional distinction between two levels of violence, the manifest and the latent. ${ }^{19}$ Manifest violence, whether personal or structural, is observable; although not directly since the theoretical entity of 'potential realization' also enters the picture. Latent violence is something which is not there, yet might easily come about. Since violence by definition is the cause of the difference (or of maintaining the nondecrease) between actual and potential realization, increased violence may come about by increases in the potential as well as by decreases in the actual levels. However, we shall limit ourselves to the latter and say that there is latent violence when the situation is so unstable that the actual realization level 'easily' decreases. For personal violence this would mean a situation where a little challenge would trigger considerable killing and atrocity, as is often the case in connection with racial fights. In such cases we need a way of expressing that the personal violence is also there the day, hour, minute, second before the first bomb, shot, fist-fight, cry - and this is what the concept of latent, personal violence does for us. It indicates a situation of unstable equilibrium, where the level of actual realization is not sufficiently protected against deterioration by upholding mechanisms.

Similarly with structural violence: we could imagine a relatively egalitarian structure insufficiently protected against sudden feudalization, against crystallization into a much more stable, even petrified, hierarchical structure. A revolution brought about by means of a highly hierarchical military organization may after a brilliant period of egalitarianism, and after major challenge, revert to a hierarchical structure. One way of avoiding this, of course, is to avoid hierarchical group struggle organizations in the first run, and use nonviolent nonhierarchical guerrilla organizations in the fight so as to let the means be a preview of the egalitarian goal. ${ }^{20}$

17 One expression of what is meant by social justice is found in declarations of human rights, where a number of norms about equality are stated. However, they very often suffer from the deficiency that they are personal more than structural. They refer to what individuals can do or can have, not to who or what decides what they can do or have; they refer to distribution of resources, not to power over the distribution of resources. In other words, human rights as usually conceived of are quite compatible with paternalism whereby power-holders distribute anything but ultimate power over the distributions, so that equalization without any change in the power structure is obtained. It is almost painful to see how few seem to realize that much of the current anti-establishment anti-authority revolt is precisely about this: concessions are not enough, not even equality is enough, it is the way in which decisions about distribution are arrived at and implemented that is basic. But there is little reason to believe that this will not also in due time crystallize into some kind of human right and be added to that list of philosophical and political battlefields.

18 Exploitation also has an ambiguity which we actually have exploited in this section. There seems to be a liberal interpretation in terms of distribution and inequality, and a Marxist interpretation in terms of power, particularly over the use of the surplus produced by others (in a capitalist economy). Clearly one can have one type of exploitation without the other.

19 I am indebted to Hans Rieger and other participants in the seminar at the Gandhian Institute of Studies for pointing out the possibility of using the manifest-latent distinction in connection with both personal and structural violence.

20 This is a point where Gandhi and Mao Tse-Tung would agree in theory, although in practice they are both so dominant in their organizations that it probably was not too meaningful to speak of real egalitarianism. 
That concludes our list of dimensions of violence, although many more could be included. One question that immediately arises is whether any combinations from these six dichotomies can be ruled out a priori, but there seems to be no such case. Structural violence without objects is also meaningful; truncation of the complete violence relation can go so far as to eliminate both subjects and objects. Personal violence is meaningful as a threat, a demonstration even when nobody is hit, and structural violence is also meaningful as a blueprint, as an abstract form without social life, used to threaten people into subordination: if you do not behave, we shall have to reintroduce all the disagreeable structures we had before.

Disregarding the negative-positive distinction as less important in this context, we end up, essentially, with the typology illustrated in Figure 1.

Figure 1: A Typology of Violence manifest

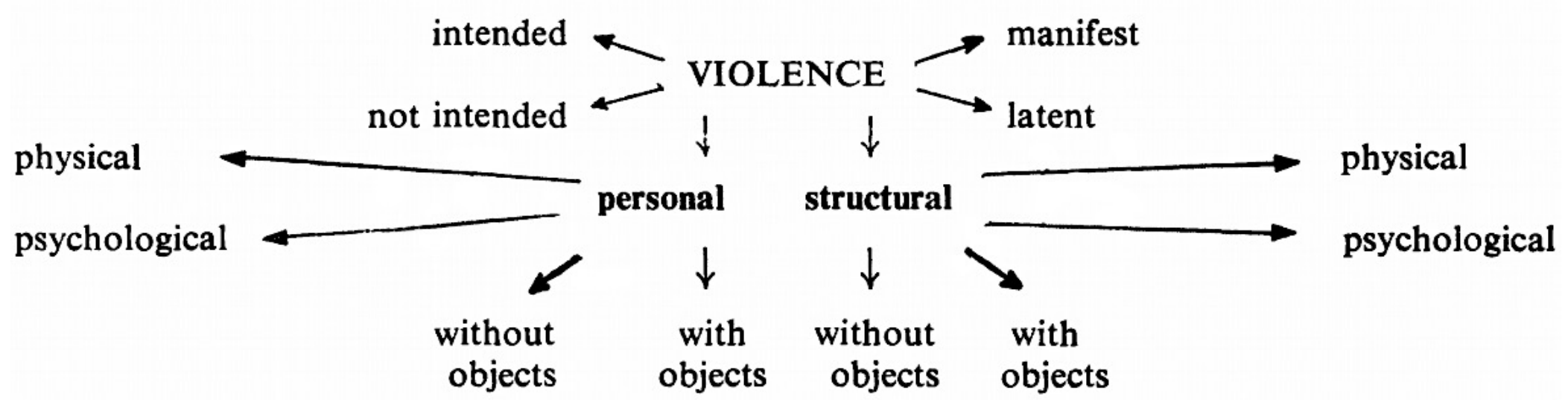

Source: Author's design.

If peace now is regarded as absence of violence, then thinking about peace (and consequently peace research and peace action) will be structured the same way as thinking about violence. And the violence cake can evidently be cut a number of ways. Tradition has been to think about violence as personal violence only, with one important subdivision in terms of 'violence vs. the threat of violence', another in terms of 'physical vs. psychological war', still another (important in ethical and legal thinking) about 'intended vs. unintended', and so on. The choice is here to make the distinction between personal and structural violence the basic one; justification has been presented (1) in terms of a unifying perspective (the cause of the difference between potential and actual realization) and (2) by indicating that there is no reason to assume that structural violence amounts to less suffering than personal violence.

On the other hand, it is not strange that attention has been focused more on personal than on structural violence. Personal violence shows. ${ }^{21}$ The object of personal violence perceives the violence, usually, and may complain - the object of structural violence may be persuaded not to perceive this at all. Personal violence represents change and dynamism - not only ripples on waves, but waves on otherwise tranquil waters. Structural violence is silent, it does not show - it is essentially static, it is the tranquil waters. In a static society, personal violence will be registered, whereas structural violence may be seen as about as natural as the air around us. Conversely: in a highly dynamic society, personal violence may be seen as wrong and harmful but still somehow congruent with the order of things, whereas structural violence becomes apparent because it stands out like an enormous rock in a creek, impeding the free flow, creating all kinds of eddies and turbulences. Thus, perhaps it is not so strange that the thinking about personal violence (in the Judaeo-Christian-Roman tradition) took on much of its present

21 See Note 13 for Carmichael's analysis. The basic point in our communication structure is of course that personal violence much more easily 'can be recorded on TV cameras', although this is not correct strictly speaking. There is no intrinsic reason why structural violence should not be registered on TV cameras; in fact, really good cameramen delight in doing exactly this. But the concept of news is against its prominent display; that concept is in itself geared to personal rather than structural violence. For an analysis, see Johan Galtung and Mari Holmboe Ruge, 'The Structure of Foreign News' (1965), especially on person vs. Structure-oriented news. 
form in what we today would regard as essentially static social orders, whereas thinking about structural violence (in the Marxist tradition) was formulated in highly dynamic northwest European societies.

In other words, we conceive of structural violence as something that shows a certain stability, whereas personal violence (e. g. as measured by the tolls caused by group conflict in general and war in particular) shows tremendous fluctuations over time. This is illustrated in Figure 2.

Figure 2: Time and the Two Types of Violence

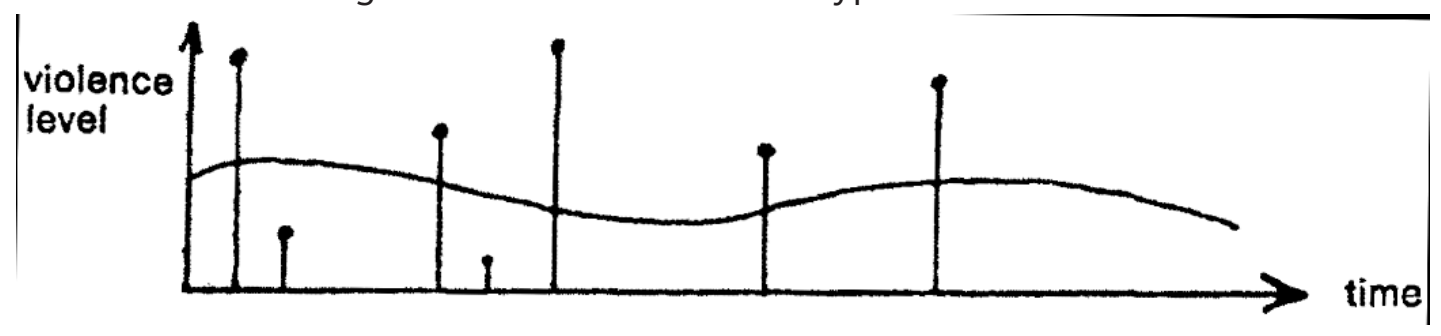

Source: Author's design.

This is to a large extent tautological. A type of violence built into the social structure should exhibit a certain stability: social structures may perhaps sometimes be changed overnight, but they may not very often be changed that quickly. Personal violence, which to a larger extent is seen as subject to the whims and wishes of individuals, should show less stability. Hence personal violence may more easily be noticed, even though the 'tranquil waters' of structural violence may contain much more violence. For this reason we would expect a focus or personal violence in after-war periods lest they should become between war periods; and if the periods protracts sufficiently for the major outburst of personal violence to be partly forgotten, we would expect a concentration on structural violence, provided the societies are dynamic enough to make any stability stand out as somehow unnatural. ${ }^{22}$

\section{THE MEANS OF PERSONAL AND STRUCTURAL VIOLENCE}

To make this distinction less abstract, let us now explore how personal and structural violence, are, in fact, carried out. Starting with personal violence, concentration on 'actual somatic realization': how can it be reduced or kept low at the hands of somebody else? The question is simple, as are the answers since they suggest an instrumental approach to the problem of violence. There is a well specified task to be done, that of doing bodily harm unto others, and there are persons available to do it. But this is a production relation, suggesting a 'development' much like in the economic sector of society, with the introduction of increasingly refined tools and differentiated social organization - only that the tools in this case are referred to as weapons or arms, and the organization is not called a workshop or a factory, but a gang or an army.

A typology of personal, physical violence can now be developed focusing on the tools used, starting with the human body itself (in the elementary forms of fist fights and the more advanced forms, such as Karate and Aikido), proceeding towards all kinds of arms culminating, so far, with $\mathrm{ABC}$ weapons. Another approach would use the form of organization, starting with the lone individual, proceeding via mobs and crowds ending up with the organizations of modern guerrilla or army warfare. These two approaches are related: just as in economic organizations the means and mode of production (here direct bodily violence) depend on each other, and if one is lagging behind a conflict will arise. Together these two approaches would yield

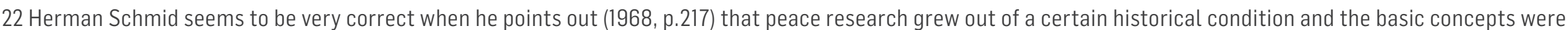

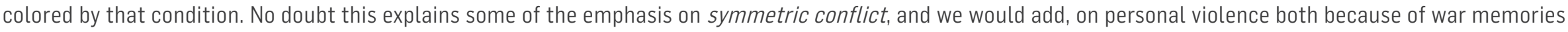

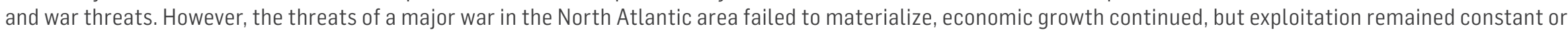

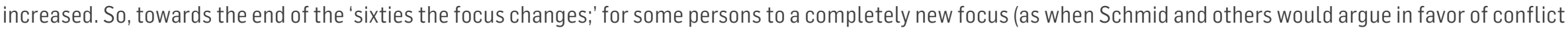
creation research, of polarization and revolution research), for others (as the present author) to an extension of focus, as argued in the present article. 
the history of military warfare as a special case, since much bodily violence is not military. The approach would be cumulative for a weapon or technique, and a form of organization once developed may become obsolete but not erased; hence this typology would not be systematic, but always open to record new developments.

Table 1. A Typology of Personal Somatic Violence

\begin{tabular}{ll}
\hline \multicolumn{1}{c}{ Focused on the anatomy } & \multicolumn{1}{c}{ Focused on the physiology } \\
\hline 1. crushing (fist fight, catapults) & 1. denial of air (choking, strangulation) \\
2. tearing (hanging, stretching, cutting) & 2. denial of water (dehydration) \\
3. piercing (knives, spears, bullets) & 3. denial of food (starvation due to siege, embargo) \\
4. burning (arson, flame, thrower) & 4. denial of movement \\
5. poisoning (in water and food, in gases) & a. by body constraint (chains, gas) \\
6. evaporation (as in nuclear explosion) & b. by space constraint (prison, detention, exile) \\
& c. by brain control (nerve gases, 'brainwashing') \\
\hline
\end{tabular}

Source: Author's design.

A more systematic approach can be obtained by looking at the target; the human being. He is relatively known anatomically (structurally) and physiologically (functionally), so typologies can be developed on that basis. One primitive typology might be as shown in Table 1. The basic distinction is not water-tight, but nevertheless useful: for one thing is to try to destroy the machine (the human body) itself, another to try to prevent the machine from functioning. The latter can be done in two ways: denial of input (sources of energy in general, air, water, and food in the case of the body), and denial of output (movement). The human output can be somatic, recorded by the outside as movement (with standstill as a limiting case) or mental not recorded directly from the outside (only by indicators in the form of movements, including movements of vocal chords). The borderline between physical and psychological personal violence is not very clear, since it is possible to influence physical movements by means of psychological techniques, and vice versa: physical constraints certainly have mental implications.

In Table 1 some of the techniques have been indicated in parenthesis. A note should be added here about explosions. In principle they are of two kinds: to propel some missile, and to work directly on human bodies. Explosions are much used for the latter purpose because they combine the anatomical methods: a standard bomb would combine 1 and 2; add some shrapnel and 3 is also taken care of; add some simple chemicals so as to make it a fire bomb and 4 is taken into account; some gases would include 5 and if in addition the contraption is made nuclear the crowning achievement, 6 , is there - presumably for ever, at least in principle, since it is difficult systematically to unmake an invention, it can only be suppressed. New weapons can always be invented, based on one or any combination of the principles in the Table. But there is also room for the more basic innovation: the introduction of a new principle.

Is it now possible to construct a corresponding typology for structural violence? If we accept that the general formula behind structural violence is inequality, above all in the distribution of power, then this can be measured; and inequality seems to have a high survival capacity despite tremendous changes elsewhere. ${ }^{23}$ But if inequality persists, then we may ask: which factors, apart from personal violence and the threat of personal violence, tend to uphold inequality? Obviously, just as military science and related subjects would be indispensable for the understanding of personal violence, so is the science of social structure, and particularly of stratification, indispensable for the understanding of structural violence.

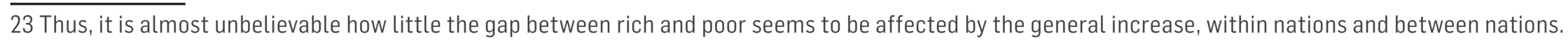


This is not the occasion to develop general theories of social structure, but some ideas are necessary to arrive at some of the mechanisms. Most fundamental are the ideas of actor, system, structure, rank and level. Actors seek goals, and are organized in systems in the sense that they interact with each other. But two actors, e.g. two nations, can usually be seen as interacting in more than one system; they not only cooperate politically, e.g. by trading votes in the UN, but also economically by trading goods, and culturally by trading ideas. The set of all such systems of interaction, for a given set of actors, can then be referred to as a structure. And in a structure an actor may have high rank in one system, low in the next, and then high in the third one; or actors may have either consistently high ranks or consistently low ranks.

However, if we look more closely at an actor, e. g. a nation, we shall very often be able to see it as a structure in its own right, but an integrated structure since it is able to appear as an actor. This 'Chinese boxes' view of actors is very important, and leads to the concept of level of actors. There are three major interpretations: ${ }^{24}$

- in terms of territories: a nation can be seen as a set of districts, in turn seen as a set of municipalities, and these are then seen as a set of individuals;

- in terms of organizations: a factory can often be seen as an assembly line with sub-factories feeding into the assemblyline with their products, finally coming down to the individual worker.

- in terms of associations: they can often be seen as consisting of local chapters, ending up with individual members.

Thus, the image of the social order or disorder can be presented as in Figure 3.

Figure 3: An Image of the Social Order

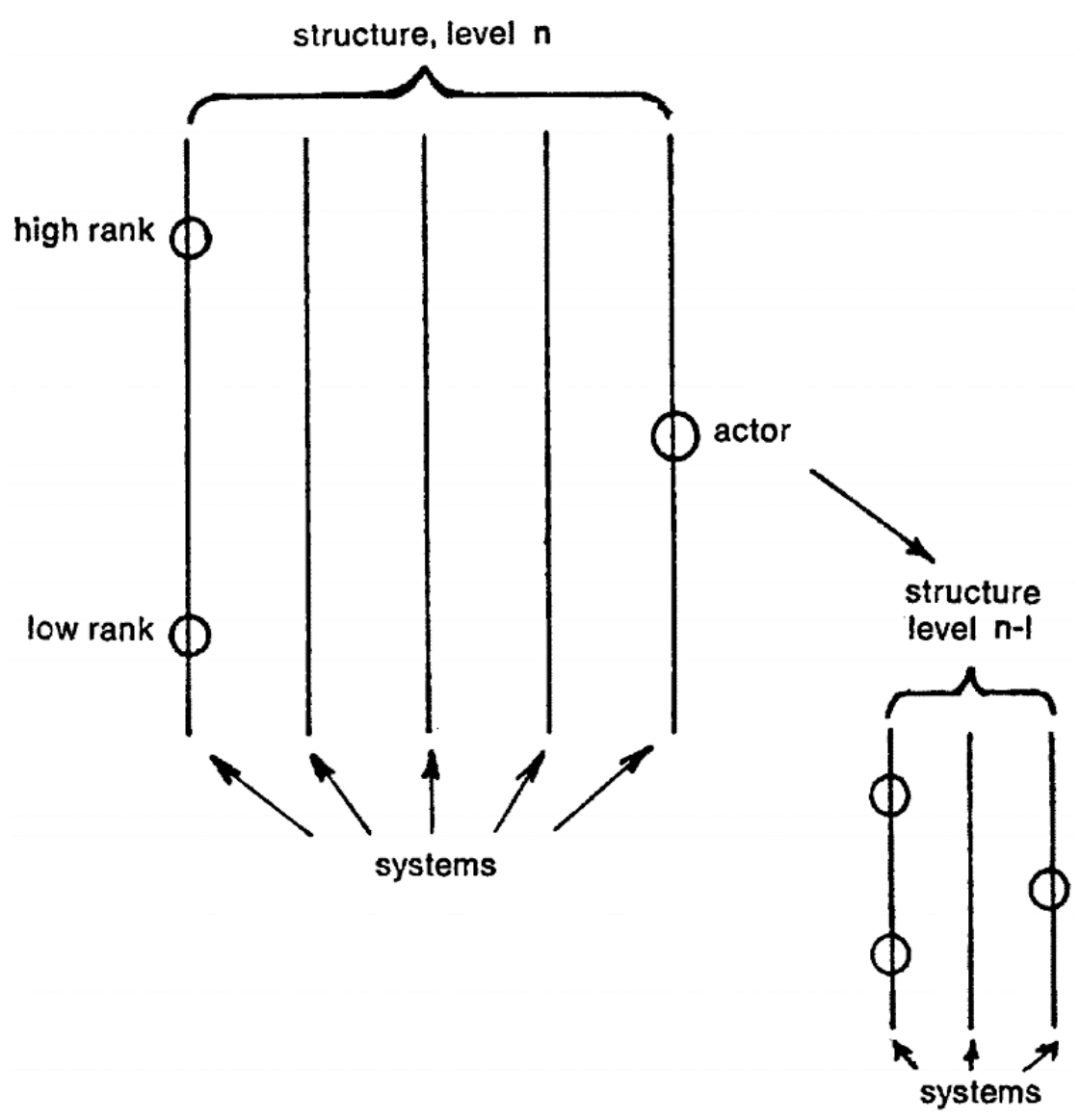

Source: Author's design.

24 This is the general theme in Johan Galtung, 'A structural Theory of Integration' (1968b). 
In all these systems there is interaction, and where there is interaction, value is somehow exchanged. It then makes very much sense to study what the value-distribution is after the system has been operating for some time, and the gross distinction has been made between egalitarian and inegalitarian distributions.

We can now mention six factors that serve to maintain inegalitarian distributions, and consequently can be seen as mechanisms of structural violence:

1. Linear ranking order - the ranking is complete, leaving no doubt as to who is higher in any pair of actors;

2. Acyclical interaction pattern-all actors are connected, but only one way there is only one 'correct' path of interaction;

3. Correlation between rank and centrality - the higher the rank of the actor in the system, the more central his position in the interaction network;

\section{Congruence between the systems - the interaction networks are structurally similar.}

5. Concordance between the ranks - if an actor is high in one system then he also tends to be high in another system where he participates and

6. High rank coupling between levels - so that the actor at level $n-1$ are represented at level $n$ through the highest ranking actor at level $n-1$.

The factors can best be understood by examining to some extent their negation, starting with the last one.

Thus, imagine that a nation is dominated by an economic and cultural capital, but has a much smaller political capital through which most political interaction in the international system is carried out. This would tend to distribute the power at the level of cities since the coupling is not at the highest point. Similarly, we could imagine that the major road from the capital to a district did not connect directly with the district point of gravity but with some peripheral point; as when a government is represented abroad not by the president or prime minister but by the foreign minister - or a sub-factory not by the manager but by his deputy. But very often the top actor at level $n-1$ is made the representative at level $n$-with a number of implications. ${ }^{25}$

Similarly, imagine there is considerable rank discordance, even to the point where the summated rankings of the actors tend to be relatively equal. In that case, patterns of inequality would be less consistent and less reinforcing, and the amount of disequilibrium in the system would also tend to upset any stability. Moreover, if the systems are not congruent but differ in structure, actors will not so easily generalize interaction patterns but be more flexible, less frozen into one way of acting (for instance servility). And if the actor with highest rank did not necessarily have the most central position in the network this would diminish his power, which would also be diminished if actors with lower ranks were to a larger extent permitted direct interaction (not only interaction mediated through the actors with high rank). Finally: nonlinear, pyramidal (also known as partial) ranking order permits more leeway, more flexibility in the system. ${ }^{26}$

25 One of these implications is of course that it enhances his power: he monopolizes information from the level above and can convert this into power at his own level. Another implication is that he is very often untrained for or unfit for the task to be performed at the higher level since his frame of reference all the time has been level $n-1$. The manager of a certain type of products suddenly finds himself on the board of a big business corporation doing quite different things; the teading nation in a regional alliance suddenly finds itself responsible for world affairs and forced to think within a completely new frame of reference, and so on. 
Many propositions can now be developed about this, a basic one being that social systems will have a tendency to develop all six mechanisms unless deliberately and persistently prevented from doing so. Thus the pattern is set for an aggravation of inequality, in some structures so much so that the lowest-ranking actors are deprived not only relative to the potential, but indeed below subsistence minimum. Inequality then shows up in differential morbidity and mortality rates, between individuals in a district, between districts in a nation, and between nations in the international system - in a chain of interlocking feudal relationships. They are deprived because the structure deprives them of chances to organize and bring their power to bear against the topdogs, as voting power, bargaining power, striking power, violent power - partly because they are atomized and disintegrated, partly because they are overawed by all the authority the topdogs present.

Thus, the net result may be bodily harm in both cases, but structural violence will probably just as often be recorded as psychological violence. Hence, highly different means may lead to highly similar results - a conclusion to be explored later.

\section{THE RELATION BETWEEN PERSONAL AND STRUCTURAL VIOLENCE}

In this section some comments will be offered on this relationship, following this outline:

1. Is there really a distinction between personal and structural violence at all?

2. If there is, does not one type of violence presuppose the manifest presence of the other?

3. If pure types exist, could it not nevertheless be said that they have a pre-history of the other type?

4. If this is not generally the case, could it not be that one type of violence presupposes the latent presence of the other?

5. If this is not the case, could it not be that one is the price we have to pay for the absence of the other?

6. If this is not generally the case, could it not be that one type is much more important in its consequences than the other?

Let us start with the first question.

It may be argued that this distinction is not clear at all: it disregards slights of the structural element in personal violence and the personal element in structural violence. These important perspectives are regained if a person is seen as making his decision to act violently not only on the basis of individual deliberations but (also) on the basis of expectations impinging on him as norms contained in roles contained in statuses through which he enacts his social self; and, if one sees a violent structure as something that is a mere abstraction unless upheld by the actions, expected from the social environment or not, of individuals. But then: does not this mean that there is no real distinction at all? Cannot a person engaging in personal violence always use expectations from the structure as an excuse, and does not a person upholding an exploitative social structure have responsibility for this?

The distinction that nevertheless remains is between violence that hits human beings as a direct result of Figure 4 type actions of others, and violence that hits them indirectly because repressive structures (as analyzed in preceding section) are upheld by the summated and concerted action of human beings. The qualitative difference between these actions is the answer. The question of guilt is certainly not a metaphysical question; guilt is as real as any other feeling, but a less interesting one. The question is rather whether violence is structured in such a way that it constitutes a direct, personal link 
ANO 15 • NÚMERO 28 • 1오. SEM. 2018 • ORGANICOM

VIOLENCE, PEACE AND PEACE RESEARCH

between a subject and an object, or an indirect structural one, not how this link is perceived by the persons at either end of the violence channel. The objective consequences, not the subjective intentions are the primary concern.

But are personal and structural violence empirically, not only logically, independent of each other? Granted that there may be a correlation so that structures richly endowed with structural violence often may also display above average incidence of personal violence, it is possible to have them in pure forms, to have one without the other? are there structures where violence is person-invariant in the sense that structural violence persists regardless of changes in persons? And conversely, are there persons where violence is structure-invariant in the sense that personal violence persists regardless of changes in structural context?

The answer seems to be yes in either case. The typical feudal structure, with a succession of incapsulating hierarchies of metropole-satellite relationships is clearly structurally violent regardless of who staffs it and regardless of the level of awareness of the participants: the violence is built into the structures. No personal violence or threat of personal violence are needed. And there are persons who seem to be violent in (almost) any setting - often referred to as 'bullies'. Characteristic of them is precisely that they carry their violent propensity with them far outside any structural context deemed reasonable by society at large, for which reason they will often be institutionalized (in prison or mental hospital, depending on which basic norms they infract first and most clearly). Hence, we may conclude that the two forms of violence are empirically independent: the one does not presuppose the other.

But from this alone it cannot be concluded that there is no necessary (not only sufficient) causal relationship between the two types of violence, or that the even stronger condition of one-way reductionism is not fulfilled. One may argue that all cases of structural violence can, by closer scrutiny, be traced back to personal violence in their pre-history. An exploitative caste system or race society would be seen as the consequence of a large-scale invasion leaving a thin, but powerful top layer of the victorious group after the noise of fighting is over. A bully would be seen as the inevitable product of socialization into a violent structure: he is the rebel, systematically untrained in other ways of coping with his conflicts and frustrations because the structure leaves him with no alternatives. That structural violence often breeds structural violence, and personal violence often breeds personal violence nobody would dispute but the point here would be the cross-breeding between the two. In other words: pure cases are only pure as long as the pre-history of the case or even the structural context are conveniently forgotten.

Far from denying that these may be fruitful perspectives both for research into the past and the etiology of violence as well as for search into the future and therapy for violence we would tend to reject the position that violence presupposes a pre-history of violence of the same or opposite kinds. This view is a breeding theory, and like all breeding theories it fails to answer two questions: how did the process come into being at all? and is spontaneous generation of violence impossible, or are all cases of violence the legitimate offspring of other cases of violence - handed down through some kind of apostolic succession, the content being more like 'original sin' though?

Take the case of structural violence first. Here it may be argued we will never get the perfect test-case. Imagine we based our thinking on something like this: people, when left to themselves in isolation (in a discussion group, stranded on an isolated island, etc.) will tend to form systems where rank, or differential evaluation of relatively stable interaction patterns referred to as status, will emerge; high ranks tend to cluster on persons who already have some high ranks, and interaction tends to flow in their direction - hence the net result is sooner or later a feudal structure. One might then object: yes, because these persons are already socialized into such structures, and all they do is to project their experiences and their habits so as to give life to an embryonic structure. And there is no way around it: human beings, to be human, have to be rated by humans, hence there will always be an element of succession. 
Maybe, but, we also suspect that the reasoning above holds true even under tabula rasa conditions because it probably is connected with the fact (1) that individuals are different and (2) that these differences somehow are relevant for their interaction behavior. Hence, special measures are needed to prevent the formation of feudal structures: structural violence seems to be more 'natural' than structural peace. And similarly with personal violence: it is difficult to see how even the most egalitarian structure would be sufficient to prevent cases of violence, whether they result from conflicts or not. Personal violence is perhaps more 'natural' than personal peace. It could also be argued that an inegalitarian structure is a built-in mechanism of conflict control, precisely because it is hierarchical, and that an egalitarian structure would bring out in the open many new conflicts that are kept latent in a feudal structure.

One could now proceed by saying that even if one type of violence does not presuppose the manifest presence of the other, neither synchronically, nor diachronically, there is nevertheless the possibility that manifest structural violence presupposes latent personal violence. When the structure is threatened, those who benefit from structural violence, above all those who are at the top, will try to preserve the status quo so well geared to protect their interests. By observing the activities of various groups and persons when a structure is threatened, and more particularly by noticing who comes to the rescue of the structure, an operational test is introduced that can be used to rank the members of the structure in terms of their interest in maintaining the structure. The involvement that does not show clearly in times of unimpeded persistence is brought up to the surface when there is turbulence. But one has to observe carefully, for those most interested in the maintenance of status quo may not come openly to the defence of the structure: they may push their mercenaries in front of them. ${ }^{27}$ In other words, they may mobilize the police, the army, the thugs, the general social underbrush against the sources of the disturbance, and remain themselves in more discrete, remote seclusion from the turmoil of personal violence. And they can do this as an extrapolation of the structural violence: the violence committed by the police is personal by our definition, yet they are called into action by expectations deeply rooted in the structure - there is no need to assume an intervening variable of intention. They simply do their job.

This view is probably generally very valid, even if it may underestimate the significance of a number of factors:

1. The extent to which the 'tools of oppression' may have internalized the repressive structure so that their personal violence is an expression of internalized, not only institutionalized norms;

2. The extent to which those who benefit from the structural violence may themselves have severe and sincere doubts about that structure and prefer to see it changed, even at their own expense;

3. The extent to which the 'challenge of the structure' may be a personal confrontation with the police etc. more than with the structure, and reveal more about the dynamics of interpersonal relations than about the structure. ${ }^{28}$

27 Few have expressed this image as well as Eldridge Cleaver in Soul on Ice (1969, p.92):

'Both police and the armed forces follow orders. Orders. Orders flow from the top down. Up there, behind closed doors, in antechambers, in conference rooms, gavels bang on the tables, the tinkling of silver decanters can be heard as ice water is poured by well fed, conservatively dressed men in horn-rimmed glasses, fashionably dressed American widows with rejuvenated faces and tinted hair, the air permeated with the square humor of Bob Hope jokes. Here all the talking is done, all the thinking, all the deciding.

Gray rabbits of men scurry forth from the conference room to spread decisions throughout the city, as News. Carrying out orders is a job, a way of meeting the payments on the house, a way of providing for one's kiddies. In the armed forces it is also a duty, patriotism.' Not to do so is treason.'

28 See Note 11 for Kahn's analysis, where he added that fighting with fists would be about as natural for the Irish cops as it is unnatural for the upper middle class student, and fighting with words as natural for that student as it is unnatural for the cop. Hence, when the student destroys property and heaps abuse on the police he challenges the police much beyond the tolerance level, and the police respond with the reaction they know, violence; a reaction for which the students are untrained. One does not need structural explanations to account for an outburst of violence in such cases. But one could ask why such people are in the police department, and one explanation can supplement rather than supersede another. 
4. The extent to which all members in a violent structure, not only the topdogs, contribute to its operation and hence are all responsible as they can all shake it through their noncooperation.

But these are minor points; social affairs always refuse to be captured in simplistic formulations. More important is whether one can also turn the proposition around and gain some insight by saying that manifest personal violence presupposes latent structural violence - which is not the same as saying that it presupposes manifest structural violence. The idea would be that of an egalitarian structure maintained by means of personal violence, so that when this pattern of violence is challenged to the point of abolition there will be an emergence of structural violence.

The proposition is interesting because it may open for some possible insights in structures yet unknown to us. It does not seem a prioriunreasonable to state that if the absence of personal violence is combined with a pattern of structural violence, then personal violence is nevertheless around the corner - and correspondingly that if absence of structural violence is combined with personal violence, then structural violence is also around the corner. All we are saying is only that the sum of violence is constant, only that one has to take into account the latent variety of the type of violence 'abolished' to see more clearly how that type is in a standby position, ready to step in once the other type crumbles. Absence of one type of violence is bought at the expense of the threat of the other.

But, however insight-stimulating this may be in certain situations we refuse to accept this pessimistic view for two reasons. First, the two propositions seem simply not to be true. It is not at all difficult to imagine a structure so purely structural in its violence that all means of personal violence have been abolished, so that when the structure is threatened there is no second trench defense by mobilizing latent personal violence. Similarly, a structure may be completely unprepared for freezing the released forces stemming from a reduction of personal violence into a hierarchical order. Empirically such cases may be rare, but yet significant.

Second, the assumption would be that human beings somehow need violence to be kept in line; if not of the personal type, then of the structural variety. The argument would be that if there is no personal violence or threat of personal violence then a very strong hierarchical order is needed to maintain order and to control conflict; and if there is no structural violence or threat of structural violence, then personal violence will easily serve as a substitute. But even if this may be a reasonable theory to explain possible empirical regularities, that in itself is not sufficient argument for reifying a regularity into a principle supposedly eternally valid. On the contrary, this would be a highly pessimistic view of the human condition, and to accept it fully would even be a capitulationist view.

From the problem of whether one type of violence is necessary to obtain or sustain the other type, whether at the manifest or the latent levels, it is not far to the opposite problem; is one type of violence necessary or sufficient to abolish the other type? The question, which actually splits into four questions, brings us directly into the center of contemporary political debate. Let us examine briefly some of the arguments.

1. Structural violence is sufficient to abolish personal violence. This thesis seems to have a certain limited and short-term validity. If all the methods mentioned above for sustaining structural violence are implemented, then it seems quite possible that personal violence between the groups segregated by the structure is abolished. The underdogs are too isolated and too awed by the topdogs, the topdogs have nothing to fear. But this only holds between those groups; within the groups the feudal structure is not practised. And although the structure probably is among the most stable social structures imaginable, it is not stable in perpetuity. There are many ways in which it may be upset, and result in tremendous outbursts of personal violence. Hence, it may perhaps be said to be a structure that serves to compartmentalize personal violence in time, leading to successions of periods of absence and presence of personal violence. 
2. Structural violence is necessary to abolish personal violence. This is obviously not true, since personal violence will cease the moment the decision not to practise it is taken. But this is of course begging the question: under what condition is that decision made and really sustained? That structural violence represents an alternative in the sense that much of the 'order' obtained by means of (the threat of) personal violence can also be obtained by (the threat of) structural violence is clear enough. But to state a relation of necessity is to go far outside our limited empirical experience.

3. Personal violence is sufficient to abolish structural violence. Again, this thesis seems to have a certain limited shortterm validity.

Personal violence directed against the topdogs in a feudal structure incapacitating them bodily by means of the techniques in Table 1, used singly or combined. When the topdogs are no longer there to exercise their roles the feudal structure can clearly no longer function. Hence, just as under 1 above between-group structural violence may be abolished by this process. But to abolish the topdogs in a violent structure is one thing, to abolish the violent structure quite another, and it is this fallacy of misplaced concreteness that is one of the strongest arguments against the proposition. The new power group may immediately fill the vacancies, retaining the structure, only changing the names of the incumbents and possibly the rationalization of the structure, in which case the structural violence is not even abolished for a short term. Or the structure may re-emerge after some time, because of internal dynamism or because it has after all been firmly imprinted on the minds of the new power-holders and has thus been present all the time in latent form.

4. Personal violence is necessary to abolish structural violence. This is, of course, a famous revolutionary proposition with a certain currency. One may argue against it on three grounds: empirically, theoretically and axiologically. Empirically one would point to all the cases of structural change decreasing structural violence that seem to take place without personal violence. The counter-argument will be that there were cases with no basic change of the structure, for if there had been a fundamental threat to the power-holders then they would have resorted to personal violence. Theoretically one would point to the qualitative difference between the means of personal and structural violence and ask: even if personal violence may lead to the abolition of structural violence, is it not likely that some, and possibly also more effective means of changing a structure would be structural, for instance systematic changes of interaction networks, rank profiles etc.? In other words, the belief in the indispensability of personal violence could be said, on theoretical grounds, to be a case of fetishization of personal violence. And then there is the axiological argument: even if personal violence could be seen as indispensable up till today, on empirical and/or theoretical grounds, this would be one more good reason for a systematic search for the conditions under which this indispensability would disappear.

Again our search seems to fail to uncover any absolutes. It is hard to sustain a belief in sufficiency or necessity one way or the other. The two types of violence simply do not seem to be more tightly connected empirically than logically - and as to the latter, the whole exercise is an effort to show that they may be seen as logically independent even though they are continuous with each other: one shades into the other.

But even if one now rejects reductionism one way or the other there would still be good reason for focusing research attention more on one kind of violence than on the other: it may always be argued than one is much more important in its consequences than the other. Thus, imagine we were able to calculate the losses incurred by the two forms of violence, or the gains that would accrue to mankind if they could be eliminated. In principle this should not be quite impossible, at least not for the simpler physical forms of violence that show up in terms of mortality, and possibly also in terms of morbidity. Mortality and morbidity rates under the condition of absence of war can usually be calculated relatively well by extrapolation from prewar and postwar data. It is more difficult for the case of absence of exploitation, but not impossible: we could calculate the levels attained if all available resources were used for the purpose of extending and improving the biological life-span and in addition were distributed in an egalitarian fashion in social space. The costs incurred by violence of one form or the other 
would then appear as the difference between the potential and the actual, as the definition requires, and the costs can then be compared. One could also imagine calculations of the costs of the joint operation of the two forms of violence.

One significant feature of such calculations, that definitely should have a high priority on the research program of peace research institutes, is that the door would be opened for answers to questions such as whether the costs in terms of personal violence were higher or lower than the gains in reduction of structural violence in, say, the Cuban revolution. The present author would say that they were definitely lower, using comparable Latin American countries as a basis for evaluating the costs of the structural violence under Batista, but in the equation one would of course also have to include the personal violence under Batista and the structural violence under Castro, e.g. in the form of almost complete alienation of the former bourgeoisie, not only as status holders, but as persons. Such statements are impressionistic however, they should be backed up empirically.

But however attractive such calculations may be - for reasons of intellectual curiosity about the dynamics of violence, structural and personal, even to develop much higher levels of theoretical insights in these phenomena than we possess today - this is not the same as accepting cost-benefit analysis in this field as a basis for political action. The point here is not so much that one may have objections to projecting the mathematical 'one human life-year = one human life-year', regardless how it is lost or gained, on to the stage of political action, but rather that this type of analysis leads to much too modest goals for political action. Imagine that the general norm were formulated 'you shall act politically so as to decrease violence, taking into account both before and after levels of personal and structural violence'. A norm of that kind would be blind to possible differences in structural and personal violence when it comes to their potential for getting more violence in the future. But it would also condone action as long as there is any decrease, and only steer political action downwards on the violence surface, not lead to a systematic search for the steepest gradient possible, even for a descent route hitherto unknown to man.

But equally important is to recall that it is hardly possible to arrive at any general judgment, independent of time and space, as to which type of violence is more important. In space, today, it may certainly be argued that research in the Americas should focus on structural violence, between nations as well as between individuals, and that peace research in Europe should have a similar focus on personal violence. Latent personal violence in Europe may erupt into nuclear war, but the manifest structural violence in the Americas (and not only there) already causes an annual toll of nuclear magnitudes. In saying this, we are of course not neglecting the structural components of the European situation, (such as the big power dominance and the traditional exploitation of Eastern Europe by Western Europe) nor are we forgetful of the high level of personal violence in the Americas even though it does not take the form of international warfare (but sometimes the form of interventionist aggression).

\section{ON THE DEFINITION OF 'PEACE' AND 'PEACE RESEARCH'}

With the distinction between personal and structural violence as basic, violence becomes two-sided, and so does peace conceived of as the absence of violence. An extended concept of violence leads to an extended concept of peace. Just as a coin has two sides, one side alone being only one aspect of the coin, not the complete coin, peace also has two sides: absence of personal violence, and absence of structural violence. ${ }^{29}$ We shall refer to them as negative peace and positive peace respectively. ${ }^{30}$

29 This coin metaphor, of course, is not to suggest that one side excludes the other. Indeed, as pointed out so many times in the preceding section: a given social order may exhibit both, one or (perhaps) neither of them. The metaphor applies to the conceptualization of peace, not to the empirical world. 
For brevity the formulations 'absence of violence' and 'social justice' may perhaps be preferred, using one negative and one positive formulation. The reason for the use of the terms 'negative' and 'positive' is easily seen: the absence of personal violence does not lead to a positively defined condition, whereas the absence of structural violence is what we have referred to as social justice, which is a positively defined condition (egalitarian distribution of power and resources). Thus, peace conceived this way is not only a matter of control and reduction of the overt use of violence, but of what we have elsewhere referred to as 'vertical development'. ${ }^{31}$ And this means that peace theory is intimately connected not only with conflict theory, but equally with development theory. And peace research, defined as research into the conditions past, present and future of realizing peace, will be equally intimately connected with conflict research and development research; the former often more relevant for negative peace and the latter more relevant for positive peace, but with highly important overlaps.

Figure 4. The Extended Concepts of Violence and Peace

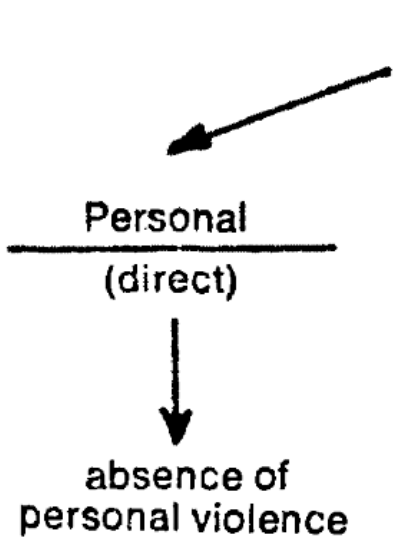
VIOLENCE
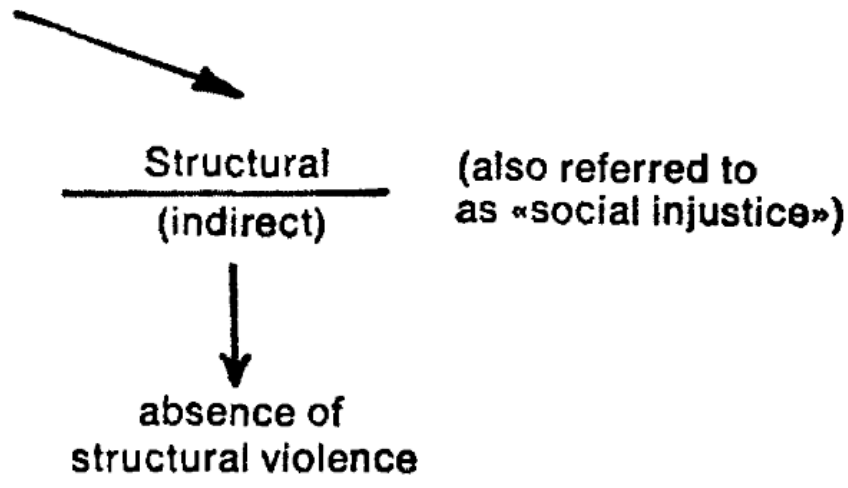

or

or

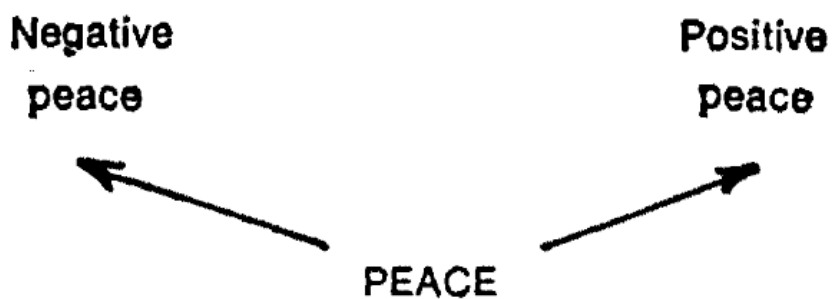

(also referred to as usocial justicen)

Source: Author's design.

To justify this way of looking at peace and peace research, let us see where the many efforts to conceive of peace in terms of only one of these 'sides' or aspects leads us. Such efforts are likely to bring into focus, in theory and indeed in practice, the onesidedness on which they are based and to highlight the need for richer concepts of peace. Here only a very sketchy outline of this type of analysis will be presented, particularly since relations between personal and structural violence were to some extent explored in the preceding section.

West conflict or a certain ideology in connection with that conflict. I would now identify 'positive peace' mainly with 'social justice', the latter taken in the double sense of this article - but I think one could also be open to other candidates for inclusion since the definition given of violence is broad enough also to point in other directions. This is to some extent attempted in section 1.3 of Theories of Peace. Moreover, I think Schmid is basically right (1968, p.221) in saying that there is a tendency to focus on negative peace because consensus is more easily obtained - but I share his rejection of that tendency. To reveal and unmask the subtle mechanisms of structural violence and explore the conditions for their removal or neutralization is at least as important, although comparisons of the two types of violence in terms of priorities seems a little bit like discussing whether medical research should focus on cancer or heart diseases. And to this should be added, emphatically, that a discipline fully satisfied with its own foundations and definition is probably a dead discipline. Fundamental debate and debate over fundamentals are the signs of health, not of disease. These issues are difficult, and we shall make progress only through more practice in analyzing them and more praxis in working with them.

31 In Theories of Development (forthcoming). 
Thus, a research emphasis on the reduction of personal violence at the expense of a tacit or open neglect of research on structural violence leads, very easily, to acceptance of 'law and order' societies. ${ }^{32}$ Personal violence is built into the system as work is built into a compressed spring in a mattress: it only shows when the mattress is disintegrating. And on the other hand there may be a research emphasis on righting social wrongs on obtaining social justice at the expense of a tacit or open acceptance and use of personal violence. The short-term costs of personal violence appear as small relative to the costs of continued structural violence. But personal violence tends to breed manifest physical violence, not only from the opponent but also inside one's own group - and the aftermath of violent revolutions generally seems to testify to this.

We may summarize by saying that too much research emphasis on one aspect of peace tends to rationalize extremism to the right or extremism to the left, depending on whether onesided emphasis is put on 'absence of personal violence' or on 'social justice'. And these two types of extremism are of course not only formally, but also socially closely related and in a dialectic manner: one is often a reaction to the other. When put into practice both may easily develop into well-known social orders where neither of the two aspects of peace are realized: gross social injustice is maintained by means of highly manifest personal violence. The regime usually tries to maintain a status quo, whether it means forceful maintenance of traditional social injustice that may have lasted for generations, or the forceful maintenance of some new type of injustice brought in by an attempt to overthrow the old system.

If 'peace' now is to be interpreted as an effort to play on both, one may ask: does this not simply mean some kind of 'moderate' course, some effort to appear 'objective' by steering carefully between the two types of extremism outlined above? There is no doubt a danger in this direction. Efforts to avoid both personal and structural violence may easily lead to accept one of them, or even both. Thus, if the choice is between righting a social wrong by means of personal violence or doing nothing, the latter may in fact mean that one supports the forces behind social injustice. And conversely: the use of personal violence may easily mean that one gets neither long-term absence of violence nor justice.

Or, we can put the argument in a slightly different framework. If we are interested in e.g. social justice but also in the avoidance of personal violence, does this not constrain our choice of means so much that it becomes meaningful only in certain societies? And particularly in societies that have already realized many social-liberal values, so that there is considerable freedom of speech and assembly, and organizations for effective articulation of political interests? Whereas we are literally immobilized in highly repressive societies, or 'more openly repressive societies' as modern critics of liberalism might say? Thus, if our choice of means in the fight against structural violence is so limited by the non-use of personal violence that we are left without anything to do in highly repressive societies, whether the repression is latent or manifest, then how valuable is this recipe for peace?

To this we may answer along many lines.

One answer would be to reject the definition given above of peace, because we want 'peace' to refer to something attainable and also in fact attained, not to something as utopian as both absence of personal violence and social justice. We may then slant the definition of 'peace' in the direction of absence of personal violence, orabsence of structural violence, depending on where our priorities are. In our definition above we have suggested that the two enter in a completely symmetrical manner: there is no temporal, logical or evaluative preference given to one or the other. Social justice is not seen as an adornment to

32 Thus, there is little doubt that in general peace research (Schmid, 1968, p.222) in this decade that has passed since it was launched has met with more approval from the north-western establishment in the world than from other quarters, but so has cancer research. From this it does not follow that peace research is meaningless to the third world and to revolutionary forces. The same skewed distribution can be found almost anywhere, due to the skewed distribution of world resources and the generally feudal structure of the world. But Schmid is certainly right in setting peace research in a social setting: 'who will pay for it', and 'who will be able to implement advice from peace researcher' are basic questions. I only fail to see that there should be any implicit reason why peace research should fall into the arms of the establishment more than into other arms not to mention be able to retain considerable autonomy in its pursuits. This presupposes an academic structure that does not steer all research into the arms of the power-holders, left or right, but leaves the road open for pursuits of insights into the mechanisms behind any kind of violence, any kind of obstacle to human self realization. 
peace as absence of personal violence, nor is absence of personal violence seen as an adornment to peace as social justice. Unfortunately, on the printed page, one has to appear before the other or above the other, and this is often interpreted as priority (compare the recent debate on whether a certain group's political slogan should be 'peace and freedom' or 'freedom and peace'). Actually, somebody should invent some way of printing so that absolutely no connotation of priority is implied.

This approach presupposes that we somehow are attracted by the term 'peace' and would like to let that word express our goal rather than some other word. But another answer would be to give up the word 'peace' and simply state our interest in one or both of the two values and then try to do our best along both dimensions, so to speak. This appears less satisfactory, because of the generally widespread use of the term 'peace' so widespread and so generally acknowledged that it possibly presents some kind of substitute in this secular age for feelings of devotion and community that in former ages were invoked by reference to religious concepts. In fact, 'peace' has indeed religious overtones to many, and that this probably contributes to the use of the word 'peace' as a carrier of feelings of universal love and brotherhood in our days. Hence, in spite of the many possibilities for semantic confusion, we would argue in favor of retaining the term 'peace'.

A third answer would be to combine the first two approaches, to talk little or at least not very loudly about peace - for fear of blushing, among other reasons - and to give up one of the two goals, absence of violence and social justice. This attitude, found today in several circles, may be commended for its honesty and lack of hypocrisy. Neither the 'law and order' racist or primitive capitalist society, nor the openly repressive post-revolutionary society is presented as realizations of 'peace', but as social orders where one made a choice between two evils, direct violence or social injustice, using what was seen as the lesser evil to drive out the greater evil (possibly ending up with both).

And then there is a fourth approach which will be preferred in this context. It may be expressed as follows:

Both values, both goals are significant, and it is probably a disservice to man to try, in any abstract way, to say that one is more important than the other. As mentioned, it is difficult to compare the amount of suffering and harm that has been caused by personal or structural violence; they are both of such an order of magnitude that comparisons appear meaningless. Moreover, they seem often to be coupled in such a way that it is very difficult to get rid of both evils; more likely the Devil is driven out with Beelzebub. In view of this difficulty, so amply testified through human history, we should be very careful in passing moral judgements too readily on those who fail to realize both goals. To realize one of them is no mean achievement either, particularly if we consider the number of social orders and regimes that realize neither.

But the view that one cannot meaningfully work for both absence of personal violence and for social justice can also be seen as essentially pessimistic, as some sort of intellectual and moral capitulationism. ${ }^{33}$ First of all, there are many forms of social action available today that combine both in a highly meaningful way. We are thinking of the tremendously rapid growth in the field of nonviolent action, both in dissociative nonviolence that serves to keep parties apart so that the weaker part can establish autonomy and identity of its own, and associative nonviolence that can serve to bring them together when a basis for equal nonexploitative partnership exists. ${ }^{34}$ We are thinking of all that is known about the theories of symmetric,

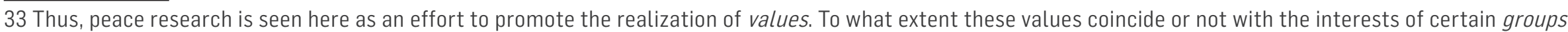

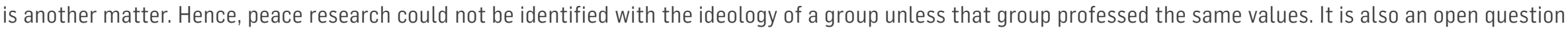
whether group identification with these values will in fact serve to promote these values.

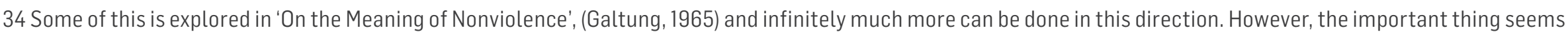

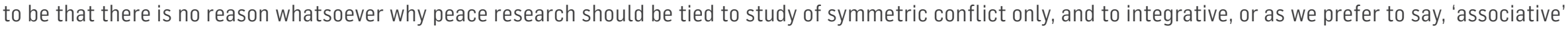

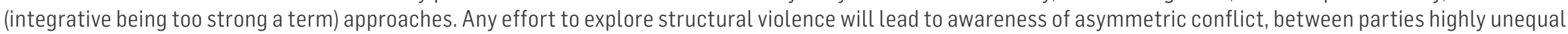

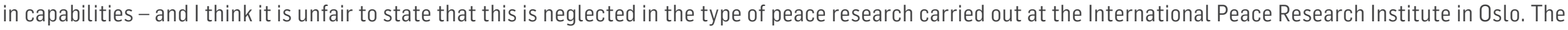

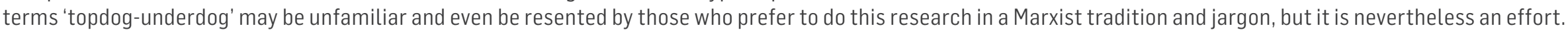

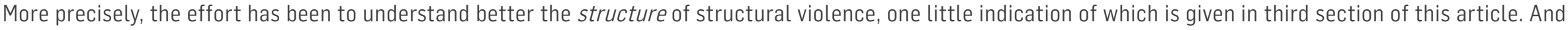

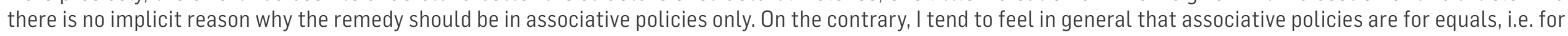


egalitarian organization in general. ${ }^{35}$ We are thinking of the expanding theory of vertical development, of participation, decentralization, codecision. And we are thinking of the various approaches to arms control and disarmament issues, although they are perhaps of more marginal significance. ${ }^{36}$ This is not the place to develop these themes; that will be done in other contexts. But secondly, once the double goal has been stated that peace research is concerned with the conditions for promoting both aspects of peace - there is no reason to believe that the future will not bring us richer concepts and more forms of social action that combine absence of personal violence with fight against social injustice once sufficient activity is put into research and practice. ${ }^{37}$ There are more than enough people willing to sacrifice one for the other - it is by aiming for both that peace research can make a real contribution.

\section{REFERENCES}

CARMICHAEL, Stokeley. Black power. In: COOPER, David (Ed.). The dialectics of liberation. London: Penguin, 1968. p. 150-174.

CLEAVER, Eldridge. Soul on ice. London: Cape, 1969.

AN EDITORIAL. Journal of Peace Research, Oslo, v. 1, n. 1, p. 1-4, 1964.

GALTUNG, Johan. On the meaning of nonviolence. Journal of Peace Research, Oslo, v. 2, n. 3, p. 228-257, 1965.

On the effects of international economic sanctions, with examples from the Case of Rhodesia. World Politics, Cambridge, UK, v. 19, n. 3, p. 387-416, 1967a.

Two approaches to disarmament: the legalist and the structuralist. Journal of Peace Research, Oslo, v. 4, n. 2 , p 161-195, 1967b.

Co-operation in Europe. Strasbourg: Council of Europe, 1968a.

symmetric conflict, whereas polarization and dissociative policies are much better strategies for exploited groups. This is also reflected in the doubleness of non-violent strategies, all themes to be more fully developed in Theories of Conflict(forthcoming). When Schmid says (1968, p.219) that peace research 'should explain [...] how latent conflicts are manifested -/and/how the present international system is seriously challenged or even broken down' he seems to betray the same type of onesidedness that he accuses peace research of -interest in controlling manifest conflicts only, in bringing about integration, in formulating problems in terms meaningful to international and supranational institutions. But this onesidedness will almost inevitably result if research shall be geared to serve the interests of specific groups, high or low, instead of the promotion of values. It is as hard to believe that disintegration, polarization, dissociation is always the best strategy as it is to believe the opposite.

But this seems to be closely related to Schmid's conflictology (1968, p.224-228), where he seems to believe that I have a subjectivistic conception of conflict. If there is anything the conflict triangle purports to achieve it is exactly the opposite: the definition of conflict independently of attitudes and behavior, and also independently of perceptions of the situation held by the parties (as different from their attitudes to each other). To me, conflict is incompatibility of goals, but how these goals are established is a quite different matter. To ask the parties for their perception of what they pursue and what, if anything, stands in the way is one, but only one approach. I have nothing against definitions in terms of 'interests' the concept of 'goal' is wide enough to encompass. The difficulty is, as Schmid readily and frankly admits (1968, p.227) to 'decide what the interests are' and I share with him the idea that 'this is a challenge rather than a reason to abandon the idea of an interest definition of conflict'. But I feel these interests have to be postulated, as I think Marx to a large extent did, and then one has to explore the implications. I also think they can be seen as expressions of values, but not necessarily held by the actor, nor necessarily held by the investigator, just as postulated values. Thus, if one feels it is contrary to the interests of children, as autonomous human beings, to accept the tie as the children of their biological parents, then there is certainly an incompatibility in the present family system: parents have interests as owners incompatible with the children's interests as self-owners. The only difference between this example and Schmid's master-slave example is that he gives a paradigm for a conflict of the past, I a paradigm for a conflict of the future, and moreover for a conflict I think will be manifested fairly soon, in line with the general wave towards defeudalization of the social order. And I certainly agree with Schmid that polarization will here be a part of the solution.

35 For an effort in this direction, see Johan Galtung, Cooperation in Europe (1968a).

36 An effort to give some reasons why are found in 'Two Approaches to Disarmament: The Legalist and the Structuralist' (Galtung, 1967b).

37 And it is of course not necessary that all or most or much of this sails under the flag of 'peace research' or any other flag for that matter - only the slightly totalitarian minded would be inclined to feel so. What is important is that it is done, and that there is contact between different approaches so that they and others can benefit from ideological and institutional pluralism. 
A structural theory of integration. Journal of Peace Research, Oslo, v. 5, n. 4, p. 375-395, 1968b.

GALTUNG, Johan; RUGE, Mari Holmboe. The structure of foreign news: the presentation of the Congo, Cuba and Cyprus crises in four Norwegian newspapers. Journal of Peace Research, Oslo, v. 2, n. 1, p. 64-90, 1965.

MARCUSE, Herbert. One-dimensional man. Boston: Beacon, 1968.

RUSSELL, Bertrand. The autobiography of Bertrand Russell: 1944-1967. London: Allen \& Unwin, 1967. v. 3.

SCHMID, Herman. Peace research and politics. Journal of Peace Research, Oslo, v. 5, n. 3, p. 217-232, 1968.

Article received on 27.02.2018 and approved on 08.04.2018. 